\title{
Study on Floral Biology of Gladiolus Genotypes
}

\author{
Tul Bahadur Poon ${ }^{1}$, T.M. Rao ${ }^{2}$, D.P. Kumar ${ }^{3}$, R. Venugopalan² and M.V.Dhananjaya ${ }^{2}$ \\ ${ }^{\prime}$ Nepal Agricultural Research Council, Nepal \\ ${ }^{2}$ Indian Institute of Horticultural Research (IIHR), Bangalore, India \\ ${ }^{3}$ University of Agricultural Sciences, GKVK, Bangalore
}

\begin{abstract}
This study was conducted in the field of Indian Institute of Horticultural Research (IIHR), Bangalore, India. The experiment was laid out in a randomized complete block design with different genotypes replicated three times. Observations were recorded for sixteen floral characters. Among different genotypes, viz., 'Arka Kesar', 'H.S.84-7-11' and 'Shobha' were early in respect of days to spike emergence, full spike emergence, the first bud showing color, basal bud loosening and flowering. Duration of spike emergence to flowering was long in 'Psittacinus hybrid' (14.18 days),' H.S.87-22-11'(13.17 days) and 'Dhiraj' (13.13 days). Duration of first floret bud loosening to complete opening of florets was short in 'Shobha' (21 hours 31 minutes), 'H.S.84-7-11'(21 hours 53 minutes) and 'Darshan '(21 hours 58 minutes). Duration of initiation and completion of anther dehiscence was long in 'Psittacinus hybrid ' (5 hours 19 minutes) and 'H.S. 82-11-27' (5 hours 7 minutes). Duration of initiation to completion of stigma receptivity was long in 'H.S. 87-22-1' (4 days 1 hour 37 minutes), 'Tilak' (4 days 1 hour) and 'H.S.87-1-1'(3 days 22 hours 59 minutes).
\end{abstract}

Key words: anther dehiscence, gladiolus, spike, stigma receptivity

\section{Introduction}

Cultivated gladiolus belongs to Genus Gladiolus, Species: grandiflorus, Order: Iridales, Family: 'Iridaceae', Subfamily: 'Iriodae' Inflorescence: Spike. In gladiolus, new varieties are evolved through hybridization. Being a flowering plant, the study of floral biology is the prerequisite for undertaking conventional breeding program so that maximum possible number of viable seeds may be produced in the shortest possible time (Mahawer \& Misra 1993). Gladiolus genotypes exhibit great variability in respect of days to flower, time of anthesis, anther dehiscence and stigma receptivity. Asynchrony in such flowering characteristics could be an impediment to plant breeders for hybridization. Gladiolus inflorescence is the spike. As such, the individual florets are attached directly to the axis. The outermost three segments make up the calyx and the next whorl of three segments comprises the corolla. The perianth surrounds three stamens and a tricarpeled pistil with a three-forked stigma. The ovary contains between 75 and 150 ovules. Each flower bud is enclosed separately within its own spathe that consists of two green bracts. The anthers dehisce within 3-4 hours after unfurling of the perianth with most of the pollen falling down on the ground or landing on the lower tepals or lip of the floret.
The position of the stigma is above anther and is not receptive until it becomes feathery (Nazir \& Dwivedi, 2006).

\section{Materials and Methods}

This study was conducted under field condition in the block VII of Indian Institute of Horticultural Research, Hessaraghatta, Bangalore during August 2006 to June 2008. The experimental field was located at an altitude of $890 \mathrm{~m}$. The soil type of the experimental site was red loam. Promising gladiolus genotypes (cultivars, hybrid selections and species) were included for the study of floral biology. The selected genotypes were: 'Aarti', 'Arka Kesar', 'Darshan', 'Dhiraj', 'Pink Friendship', 'Kum Kum', 'Shobha', 'Tilak', 'Hybrid selection 8211-27', 'Hybrid selection 84-7-11', 'Hybrid selection 87-1-1', 'Hybrid selection 87-22-1', 'Hybrid selection 88-4-8', 'Gladiolus callianthus' and 'Psittacinus hybrid'.

The experiment was laid out in a randomized complete block design with different gladiolus genotypes replicated three times. Twenty eight corms having $5 \mathrm{~cm}$ average diameter that were about to sprout 
were planted per replication in $2.4 \mathrm{~m}^{2}$ bed. On the whole, four representative plants were selected randomly from each replication. The selected plants were labeled for the convenience of observing the characters included in the study of floral biology. Observations were made on a total of 16 floral biological characters viz., days to spike emergence, days to full spike emergence, days to bud separation, days to first bud showing color, days to first basal bud loosening, days to flowering, duration of spike emergence to flowering, time of floret bud loosening, time of complete floret opening, time of the initiation of anther dehiscence, time of completion of anther dehiscence, time of initiation of stigma receptivity ,time of completion of stigma receptivity, duration of first basal floret loosening to complete opening of floret, duration of initiation to completion of anther dehiscence, duration of initiation to completion of stigma receptivity.

\section{Results}

Highly significant differences were observed for all characters studied in different genotypes of gladiolus. The results of the analyzed data are presented in Table 1 to 3. Days to spike emergence varied from 56.56 to 71.85 days with a mean of 63.95 days (Table 1 ). Genotype 'Arka Kesar' was earliest (56.56 days) followed by 'Hybrid selection 84-7-11' (57.23 days) and 'Shobha' (58.89 days); however, 'Arka Kesar' was statistically at par with 'Hybrid selection 84-7-11', 'Shobha' and 'Hybrid selection 88-4-8' in this regard. The genotype 'Dhiraj' was late (71.85 days) to spike emergence followed by 'Hybrid selection 82-11-27' (71.42 days) and 'Tilak' (71.06 days) and these three genotypes were statistically at par.

Days to full spike emergence varied from 59.28 days to 75.21 days with a mean value of 67.10 days (Table 1 ). The genotype 'Arka Kesar' required the minimum number of days (59.28) for full spike emergence followed by 'Hybrid selection 84-7-11' (60.19 days) and 'Shobha' (61.68 days). Genotypes viz., 'Arka Kesar' was at par with 'Hybrid selection 84-7-11' and 'Shobha'. The maximum number of days (75.21 days) were required for 'Dhiraj'. The genotypes viz., 'Dhiraj', 'Hybrid selection 82-11-27' and 'Tilak' were statistically at par.

Days to bud separation varied from 62.29 days to 77.92 days with a mean value of 69.93 days (Table 1). Genotype 'Arka Kesar' needed the minimum number of days (62.29 days) to bud separation followed by 'Hybrid selection 84-7-11' (62.44 days) and 'Shobha' (64.23 days).
However, genotypes viz., 'Arka Kesar', 'Hybrid selection 84-7-11', 'Shobha', and 'Hybrid selection 88-4-8' showed statistically non-significant variations. 'Dhiraj' required the maximum number of days (77.92 days). In terms of variation for the character, genotypes such as 'Dhiraj' was also found statistically on par with 'Hybrid selection 82-11-27' (77.14 days), 'Tilak' (76.71 days) and 'Psittacinus hybrid' (73.76 days).

The variations of days to first bud showing color ranged from 64.28 days to 81.39 days with a mean value of 72.74 days (Table 1). Genotype 'Hybrid selection 847-11' showed the first bud color in earliest (64.28 days) followed by 'Arka Kesar' (64.43 days) and 'Shobha' (67.23 days). Genotype viz., 'Hybrid selection 84-7-11' did not vary statistically from 'Arka Kesar', and 'Shobha'. 'Dhiraj' showed color in the first bud late (81.39 days) followed by 'Hybrid selection 82-11-27' (80.58 days) and 'Tilak' (79.64 days). Yet the variations for this character among genotypes viz., 'Dhiraj' 'Hybrid selection 82-11-27', 'Tilak' and 'Psittacinus hybrid' were statistically not significant.

Variations of days to first basal bud loosening were from 66.39 days to 83.88 days with a mean value of 74.99 days (Table 1). In the genotype 'Hybrid selection 84-7-11', the first basal bud loosening was the earliest (66.39 days) and genotype 'Arka Kesar' and 'Shobha' followed with 66.62 days and 69.05 days respectively. With this regard, all these three genotypes were on par. The genotype 'Dhiraj' showed the first basal bud loosening late ( 83.88 days) followed by 'Tilak' ( 82.75 days) and 'Hybrid selection 82-11-27' (82.71 days). Variations were statistically not significant among genotypes viz., 'Dhiraj', 'Tilak' and 'Hybrid selection 82-11-27'.

Days to flowering varied from 67.39 days to 84.88 days with a mean value of 75.99 days (Table 1). Genotype 'Hybrid selection 84-7-11' was the earliest (67.39 days) to flower followed by 'Arka Kesar' (67.62 days) and 'Shobha' (70.05 days). However, the variations among genotypes viz., 'Hybrid selection 847-11', 'Arka Kesar' and 'Shobha', were not significant. Even though 'Dhiraj' took maximum days ( 84.88 days), yet it was statistically on par with genotypes 'Tilak' (83.75 days), 'Hybrid selection 82-11-27' (83.71 days) and 'Psittacinus hybrid' (80.99 days).

Duration of spike emergence to flowering varied from 10.17 days to 14.18 days with a mean value of 12.09 
days (Table 1). Minimum duration (10.17 days) was in genotype 'Hybrid selection 84-7-11'. On the other hand, differences for the character in genotypes viz., 'Arka Kesar' (11.12 days), 'Shobha' (11.13 days), 'Darshan' (11.49 days), 'Hybrid selection 87-1-1' (11.72 days) and 'Hybrid selection 88-4-8' (11.79 days) were found statistically on par with 'Hybrid selection 84-7-11'. The longest duration of spike emergence to flowering was recorded in 'Psittacinus hybrid' (14.18 days) followed by 'Hybrid selection 87-22-1' (13.17 days) and 'Dhiraj' (13.13 days). However, variations for this character among genotypes viz., 'Psittacinus hybrid', 'Hybrid selection 87-22-1', 'Dhiraj' and 'Tilak' was statistically on par.

Table 1. Evaluation of different genotypes of gladiolus for floral characters

\begin{tabular}{l|l|l|l|l|l|l|l}
\hline \multicolumn{1}{|c|}{ Genotypes } & $\begin{array}{l}\text { Days to spike } \\
\text { emergence }\end{array}$ & $\begin{array}{l}\text { Days to } \\
\text { full spike } \\
\text { emer- } \\
\text { gence }\end{array}$ & $\begin{array}{l}\text { Days to } \\
\text { bud } \\
\text { separation }\end{array}$ & $\begin{array}{l}\text { Days to first } \\
\text { bud showing } \\
\text { color }\end{array}$ & $\begin{array}{l}\text { Days to } \\
\text { first basal } \\
\text { bud } \\
\text { loosening }\end{array}$ & $\begin{array}{l}\text { Days to } \\
\text { flowering }\end{array}$ & $\begin{array}{l}\text { Duration } \\
\text { of spike } \\
\text { emer- } \\
\text { gence to } \\
\text { flowering } \\
\text { (Days) }\end{array}$ \\
\hline Aarti & 62.44 & 65.47 & 67.98 & 72.52 & 73.84 & 74.84 & 12.31 \\
Arka Kesar & 56.56 & 59.28 & 62.29 & 64.43 & 66.62 & 67.62 & 11.12 \\
Darshan & 63.21 & 66.96 & 69.59 & 71.50 & 73.62 & 74.62 & 11.49 \\
Dhiraj & 71.85 & 75.21 & 77.92 & 81.39 & 83.88 & 84.88 & 13.13 \\
Kum Kum & 63.62 & 66.15 & 72.45 & 72.11 & 74.55 & 75.55 & 11.92 \\
Shobha & 58.89 & 61.68 & 64.23 & 67.23 & 69.05 & 70.05 & 11.13 \\
Tilak & 71.06 & 74.23 & 76.71 & 79.64 & 82.75 & 83.75 & 12.63 \\
H.S.82-11-27 & 71.42 & 74.64 & 77.14 & 80.58 & 82.71 & 83.71 & 12.37 \\
H.S.84-7-11 & 57.23 & 60.19 & 62.44 & 64.28 & 66.39 & 67.39 & 10.17 \\
H.S.87-1-1 & 62.92 & 66.67 & 69.07 & 71.27 & 73.68 & 74.68 & 11.72 \\
H.S.87-22-1 & 64.61 & 67.00 & 69.24 & 74.15 & 76.24 & 77.24 & 13.17 \\
H.S.88-4-8 & 60.69 & 64.34 & 66.24 & 69.38 & 71.53 & 72.53 & 11.79 \\
P. hybrid & 66.80 & 70.49 & 73.76 & 77.11 & 79.99 & 80.99 & 14.18 \\
Mean & 63.95 & 67.10 & 69.93 & 72.74 & 74.99 & 75.99 & 12.09 \\
F-test & $* *$ & $* *$ & $* *$ & $* *$ & $* *$ & $* *$ & $* *$ \\
CD @ 5\% & 4.29 & 4.54 & 5.42 & 4.79 & 4.90 & 4.90 & 1.68 \\
\hline
\end{tabular}

$P$. hybrid $=$ Psittacinus hybrid, H.S. $=$ Hybrid selection

Time (O'clock) of floret bud loosening (FBL) ranged from 7.20 a.m. in 'Psittacinus hybrid' to 12.04 p.m. in 'Darshan' (Table 2). Floret bud loosened the earliest in 'Psittacinus hybrid' followed by 'Hybrid selection 847-11' at 8.00 a.m. and 'Hybrid selection 87-22-1' at 8.20 a.m. Floret bud loosening was late in 'Darshan' followed by 'Hybrid selection 88-4-8' at 11.07 a.m. and 'Kum Kum' at 10.26 a.m.
Time (O'clock) of complete floret opening (CFO) ranged from 5.53 a.m. to 11.56 a.m. (Table 2). It was early in genotypes viz., 'Hybrid selection 84-7-11' at 5.53 a.m., 'Shobha' at 6.20 a.m. and 'Hybrid selection 87-22-1' at 9.43 a.m. while the mean time of complete floret opening was late in genotypes viz., 'Dhiraj' at 11.56 a.m., 'Tilak' at 11.41 a.m. and 'Arka Kesar' at 11.40 a.m. 
Table 2. Mean time recorded at floret bud loosening (FBL), complete floret opening (CFO), initiation of anther dehiscence (IAD), completion of anther dehiscence(CAD), stigma receptivity initiation (SRI) and stigma receptivity completion (SRC) in different genotypes of gladiolus.

\begin{tabular}{|c|c|c|c|c|c|c|}
\hline Genotypes & $\begin{array}{l}\text { Mean } \\
\text { time } \\
\text { (O'clock) } \\
\text { of } \\
\text { FBL }\end{array}$ & $\begin{array}{l}\text { Mean } \\
\text { time } \\
\text { (O'clock) } \\
\text { of } \\
\text { CFO }\end{array}$ & $\begin{array}{l}\text { Mean } \\
\text { time } \\
\text { (O'clock) } \\
\text { of IAD }\end{array}$ & $\begin{array}{l}\text { Mean } \\
\text { time } \\
\text { (O'clock) } \\
\text { of CAD }\end{array}$ & $\begin{array}{l}\text { Mean } \\
\text { time } \\
\text { (O'clock) } \\
\text { of SRI }\end{array}$ & $\begin{array}{l}\text { Mean } \\
\text { time } \\
\text { (O'clock) of } \\
\text { SRC }\end{array}$ \\
\hline Aarti & 10.23 a.m. & $11.12 \mathrm{a} . \mathrm{m}$. & 9.55 a.m. & 2.10 p.m. & 12.23 p.m. & 10.26 a.m. \\
\hline Arka Kesar & 8.26 a.m. & 11.40 a.m. & 9.31 a.m. & 1.26 p.m. & 10.30 p.m. & 2.37 p.m. \\
\hline Darshan & 12.04 p.m. & 10.02 a.m. & 8.55 a.m. & 1.33 p.m. & 3.50 p.m. & 2.13 p.m. \\
\hline Dhiraj & 9.53 a.m. & 11.56 a.m. & 9.20 a.m. & 1.41 p.m. & 12.47 p.m. & 11.35 a.m. \\
\hline Kum Kum & 10.26 a.m. & 10.20 a.m. & 9.58 a.m. & 2.14 p.m. & 12.53 p.m. & 3.53 p.m. \\
\hline Pink Friendship & 9.07 a.m. & 9.53 a.m. & 9.04 a.m. & 12.50 p.m. & 9.38 a.m. & 7.57 a.m. \\
\hline Shobha & 8.57 a.m. & 6.20 a.m. & 9.44 a.m. & 1.21 p.m. & 11.20 a.m. & 8.56 a.m. \\
\hline Tilak & 8.35 a.m. & 11.41 a.m. & 9.52 a.m. & 2.17 p.m. & 11.13 a.m. & 12.13 p.m. \\
\hline H.S. $82-11-27$ & 10.10 a.m. & 11.23 a.m. & 8.34 a.m. & 1.59 p.m. & 12.10 p.m. & 11.02 a.m. \\
\hline H.S.84-7-11 & 8.00 a.m. & 5.53 a.m. & 8.59 a.m. & 1.30 p.m. & 9.13 a.m. & 1.00 p.m. \\
\hline H.S.87-1-1 & 9.13 a.m. & 11.00 a.m. & 9.14 a.m. & 1.26 p.m. & 1.33 p.m. & 12.46 p.m. \\
\hline H.S.87-22-1 & 8.20 a.m. & 9.43 a.m. & 8.50 a.m. & 1.25 p.m. & 11.32 a.m. & 12.50 p.m. \\
\hline H.S.88-4-8 & 11.07 a.m. & 10.20 a.m. & 9.43 a.m. & 1.20 p.m. & 1.40 p.m. & 3.20 p.m. \\
\hline Gladiolus callianthus & 8.37 a.m. & 11.15 a.m. & 5.59 a.m. & 10.09a.m. & 11.43 a.m. & 6.41 a.m. \\
\hline Psittacinus hybrid & 7.20 a.m. & 10.07 a.m. & 8.16 a.m. & 1.37 p.m. & 9.20 a.m. & 2.53 p.m. \\
\hline
\end{tabular}

Time (O'clock) of the initiation of anther dehiscence (IAD) was from 5.59 a.m. to 9.58 a.m. (Table 2). The mean time for the initiation of anther dehiscence occurred the earliest at 5.59 a.m. in 'Gladiolus callianthus' followed by 'Psittacinus hybrid' at 8.16 a.m. and 'Hybrid selection 82-11-27' at 8.34 a.m. The mean time for the initiation of anther dehiscence was late at 9.58 a.m. in 'Kum Kum' followed by 'Aarti' at 9.55 a.m. and 'Tilak' at 9.52 a.m.

Time (O'clock) of the completion of anther dehiscence (CAD) was from 10.09 a.m. to 2.17 p.m. (Table 2). The mean time for completion of anther dehiscence in 'Gladiolus callianthus' was at 10.09 a.m. which was much earlier than other genotypes. This was followed by genotype 'Pink Friendship' at 12.50 p.m. and 'Hybrid selection $88-4-8$ ' at 1.20 p.m. whereas mean time for the completion of anther dehiscence was late in genotypes viz., 'Tilak' at 2.17 p.m., 'Kum Kum' at 2.14 p.m. and 'Aarti' at 2.10 p.m.

Time (O'clock) of stigma receptivity initiation (SRI) varied from 9.13 a.m. to 3.50 p.m. (Table 2). It was early in genotype viz., 'Hybrid selection 84-7-11' at 9.13 a.m. followed by 'Psittacinus hybrid' at 9.20 a.m. and 'Pink
Friendship' at 9.38 a.m. The mean time for the initiation of stigma receptivity was late in genotype viz., 'Darshan' at 3.50 p.m. followed by 'Hybrid selection $88-4-8$ ' at 1.40 p.m. and 'Hybrid selection $87-1-1$ ' at 1.33 p.m.

Time (O'clock) of completion of stigma receptivity (CSR) varied from 6.41 a.m. to 3.53 p.m. (Table 2). With respect to mean time for completion of stigma receptivity, it was the earliest in the genotype 'Gladiolus callianthus' at 6.41 a.m. followed by 'Pink Friendship' at 7.57 a.m. and 'Shobha' at 8.56 a.m. whereas it was late in cv. 'Kum Kum 'at 3.53 p.m. followed by 'Hybrid selection $88-4-8$ ' at 3.20 p.m. and' Psittacinus hybrid' at 2.53 p.m'.

Duration of first floret loosening (FFL) to complete opening of florets varied from 1291 minutes (21 hours 31 minutes) in genotype 'Shobha' to 1614.67 minutes (26 hours 55 minutes) in 'Tilak' with the mean value of 1487.10 minutes (24 hours 47 minutes) (Table 3 ). In respect of this character, the genotype 'Shobha' had the shortest period with 1291 minutes ( 21 hours 31 minutes) followed by 'Hybrid selection 84-7-11' with 1313.33 minutes ( 21 hours 53 minutes) and 'Darshan' with 1317.68 minutes (21 hours 58 minutes). However,all 
these three genotypes were statistically on par; whereas the longest duration was recorded in genotype 'Tilak' with 1614.67 minutes (26 hours 55 minutes) followed by 'Psittacinus hybrid' with 1600 minutes (26 hours 40 minutes) and 'Gladiolus callianthus' with 1597.67 minutes (26 hours 38 minutes). The genotypes viz., 'Tilak', 'Psittacinus hybrid', 'Gladiolus callianthus', 'Arka Kesar' and 'Dhiraj' were statistically on par.

Duration of initiation of anther dehiscence to completion of anther dehiscence varied from 206 minutes (3 hours 26 minutes) in genotype 'Shobha' to 318.67 minutes (5 hours 19 minutes) in 'Psittacinus hybrid' with the mean value of 260.47 minutes ( 4 hours 20 minutes) (Table 3). In respect of this character, 'Shobha' took the shortest period with 206 minutes (3 hours 26 minutes) followed by 'Hybrid selection $88-4-8$ ' with 216.67 minutes ( 3 hours 37 minutes) and 'Pink Friendship' with 226.67 minutes ( 3 hours 49 minutes); however, the genotypes viz., 'Shobha' 'Hybrid selection 88-4-8' 'Pink Friendship' 'Arka Kesar' 'Aarti' 'Hybrid selection 87-1-1' and 'Dhiraj' were statistically on par. While genotype 'Psittacinus hybrid' took the longest period with 318.67 minutes ( 5 hours 19 minutes) which was statistically on par with 'Hybrid selection 82-11$27^{\prime}$ 'with 306.67 (5 hours 7 minutes), 'Darshan' as well as
'Hybrid selection 84-7-11' with 284.33 minutes (4 hours 44 minutes) and 'Kum Kum' with 268.33 minutes (4 hours 28 minutes).

Duration of initiation of stigma receptivity to completion of stigma receptivity varied from 4420.00 minutes ( 3 days 1 hour 40 minutes) to 5856.67 minutes (4 days 1 hour 37 minutes) with the mean value 5400.38 minutes (3 days 18 hours) (Table 3 ). The genotype 'Hybrid selection 87-22-1' had the longest period of stigma receptivity with 5856.67 minutes ( 4 days 1 hour 37 minutes) followed by 'Tilak' with 5820 minutes (4 days I hour) and 'Hybrid selection 87-1-1' with 5700.00 minutes ( 3 days 22 hours 59 minutes); however, the differences for the character in genotypes viz., Hybrid selection 87-22-1', 'Tilak', 'Hybrid selection 87-1-1', 'Hybrid selection 82-11-27', 'Darshan', 'Pink Friendship' and 'Aarti' were found statistically on par. The genotype 'Hybrid selection 88-4-8' recorded the shortest duration of stigma receptivity with 4420.00 minutes ( 3 days 1 hour 40 minutes) followed by 'Hybrid selection $84-7-11$ ' with 4546.67 minutes (3 days 3 hours 46 minutes) and 'Arka Kesar' with 4566.67 minutes ( 3 days 4 hours 7 minutes) but the differences for these three genotypes were not statistically significant.

Table 3. Performance of different genotypes of gladiolus in respect of floral biological

\begin{tabular}{|c|c|c|c|}
\hline Genotypes & $\begin{array}{l}\text { Duration of first } \\
\text { basal floret } \\
\text { loosening to } \\
\text { complete opening } \\
\text { of floret (minutes) }\end{array}$ & $\begin{array}{l}\text { Duration of initiation } \\
\text { of anther dehiscence to } \\
\text { completion of anther } \\
\text { dehiscence (minutes) }\end{array}$ & $\begin{array}{l}\text { Duration of stigma } \\
\text { receptivity initiation to } \\
\text { completion of stigma } \\
\text { receptivity (minutes) }\end{array}$ \\
\hline Aarti & $1489.00(24 \mathrm{hrs} 49 \mathrm{~min})$ & 254.67 (4 hrs14 min) & $5643.33(3$ days $22 \mathrm{hrs} 3 \mathrm{~min})$ \\
\hline Arka Kesar & $1574.00(26 \mathrm{hrs} 14 \mathrm{~min})$ & 235.67 ( 3 hrs 56 min $)$ & $4566.67(3$ days 4 hrs $7 \mathrm{~min})$ \\
\hline Darshan & 1317.68 (21 hrs $58 \mathrm{~min})$ & 284.33 (4 hrs $44 \mathrm{~min})$ & 5663.33 ( 3 days $22 \mathrm{hrs} 23 \mathrm{~min}$ ) \\
\hline Dhiraj & $1563.33(26 \mathrm{hrs} 3 \mathrm{~min})$ & 260.33 (4 hrs $20 \mathrm{~min})$ & 5710.00 ( 3 days $23 \mathrm{hrs} 11 \mathrm{~min})$ \\
\hline Kum Kum & $1500.00(25 \mathrm{hrs})$ & 268.33 (4 hrs $28 \mathrm{~min})$ & $5220.00(3$ days $15 \mathrm{hrs})$ \\
\hline Pink Friendship & $1486.68(24 \mathrm{hrs} 47 \mathrm{~min})$ & 226.67 (3 hrs $49 \mathrm{~min})$ & 5662.33 ( 3 days $22 \mathrm{hrs} 23 \mathrm{~min})$ \\
\hline Shobha & $1291.00(21 \mathrm{hrs} 31 \mathrm{~min})$ & 206.00 (3 hrs $26 \mathrm{~min})$ & 5616.67 ( 3 days $21 \mathrm{hrs} 36 \mathrm{~min}$ ) \\
\hline Tilak & $1614.67(26 \mathrm{hrs} 55 \mathrm{~min})$ & 266.67 (4 hrs $26 \mathrm{~min})$ & 5820.00 (4 days $1 \mathrm{hr})$ \\
\hline Hybrid sel.82-11-27 & $1512.33(25 \mathrm{hrs} 12 \mathrm{~min})$ & 306.67 (5 hrs $7 \mathrm{~min})$ & 5690.00 (3days $22 \mathrm{hrs} 49 \mathrm{~min})$ \\
\hline Hybrid sel.84-7-11 & 1313.33 (21 hrs $53 \mathrm{~min})$ & 284.33 (4 hrs $44 \mathrm{~min})$ & $4546.67(3$ days 3 hrs $46 \mathrm{~min})$ \\
\hline Hybrid sel.87-1-1 & 1546.67 (25 hrs $47 \mathrm{~min})$ & 252.67 (4 hrs $13 \mathrm{~min})$ & 5700.00 ( 3 days $22 \mathrm{hrs} 59 \mathrm{~min})$ \\
\hline Hybrid sel.87-22-1 & $1523.33(25 \mathrm{hrs} 23 \mathrm{~min})$ & 276.33 (4 hrs $37 \mathrm{~min})$ & 5856.67 (4 days $1 \mathrm{hr} 37 \mathrm{~min})$ \\
\hline Hybrid sel.88-4-8 & 1376.67 (22 hrs $56 \mathrm{~min})$ & 216.67 (3 hrs $37 \mathrm{~min})$ & 4420.00 ( 3 days $1 \mathrm{hr} 40 \mathrm{~min})$ \\
\hline Gladiolus callianthus & 1597.67 (26 hrs $38 \mathrm{~min})$ & $249.00(4 \mathrm{hrs} 9 \mathrm{~min})$ & 5456.67 ( 3 days $18 \mathrm{hrs} 56 \mathrm{~min}$ ) \\
\hline Psittacinus hybrid & $1600.00(26 \mathrm{hrs} 40 \mathrm{~min})$ & 318.67 (5 hrs $19 \mathrm{~min})$ & 5433.33 ( 3 days $18 \mathrm{hrs} 33 \mathrm{~min}$ ) \\
\hline Mean & $1487.10(24 \mathrm{hrs} 47 \mathrm{~min})$ & $260.47(4 \mathrm{hrs} 20 \mathrm{~min})$ & 5400.38 ( 3 days $18 \mathrm{hrs})$ \\
\hline F-test & & & $* *$ \\
\hline C.D.@ $9 \%$ & 55.127 & 50.487 & 358.620 \\
\hline
\end{tabular}

** Highly significant 


\section{Discussion}

Floral biology was studied in different promising genotypes of gladiolus, and results of the experiment are discussed below.

For the characters such as days to spike emergence, days to full spike emergence, and days to bud separation, genotypes such as 'Arka Kesar', 'Hybrid selection 84-7-11' and 'Shobha' were early in comparison to other genotypes. Moreover, the characters viz., days to the first bud showing color, days to first basal bud loosening, days to flowering and duration of spike emergence to flowering were consistently early in the same three genotypes viz., 'Hybrid selection 84-7-11', 'Arka Kesar' and,'Shobha' among different genotypes evaluated. In the present study, the number of days for early spike emergence ranged from 56.56 days ('Arka Kesar') to 58.89 days ('Shobha'). The result of the present study agrees with the result of Nagraju and Parthsarathy (2001) as they recorded the early spike emergence in genotypes viz., 'Meera', 'Beauty Spot' and 'Yellow Mix' ranging from 57.00 days to 59.3 days whereas Mohanty (2006) found the earliest spike emergence in genotypes viz., 'Dhavantari' (51 days),'Anglia' (51.10 days) and 'Bindya' (56.33 days), in which spike emergence is a little earlier in their study than in the present study. Slight variations were due to the differences of geographical location, genotypes, cultural management and growing season.

In the present study, days for the first bud showing color was also early in genotypes viz., 'Hybrid selection 84-7-11' (64.28 days), 'Arka Kesar' (64.43 days) and 'Shobha' (67.23 days). Kumar and Yadav (2006) recorded the first floret showing color as early in 'Smoky Lady' (71.22 days). Despite different genotypes evaluated, the present finding is nearly in accordance with the finding of Kumar and Yadav (2006).

For the first bud separation Shah et al. (1988) reported genotypes viz., 'Carmine' (79.00 days), 'Spite' (80 days) and 'Gospel Song' (80.50 days) as early under temperate conditions. While in the present study, days to first bud separation was early in genotypes viz., 'Arka Kesar'(62.29 days) 'Hybrid selection 84-7-11' (62.44 days), and 'Shobha (64.23 days) under Bangalore condition'. In the present study the first floret bud separation was earlier than those of the genotypes reported by Shah et al. (1988) that is mostly due to the influences of different genotypic and climatic conditions.

In the present study, days to flowering was early in 'Hybrid selection 84-7-11', 'Arka Kesar' and 'Shobha'. Days to flowering varied from 67.39 days to 84.88 days among different genotypes evaluated. Whereas Katwate et al. (2005) reported that it varied from 55.56 days to 119.67 days. Their findings indicate more variations for this character than those of the present study due to inclusion of quite different genotypes in their study.

The overall mean time of floret bud loosening was early in 'Psittacinus hybrid' 'Hybrid selection 84-7-11' and 'Hybrid selection 87-22-1'. The initiation time of floret bud loosening was quite earlier in 'Hybrid selection 87-22-1' (5.0 a.m.) than in any of the genotypes studied. Among the genotypes studied in 'Darshan' floret bud loosening was late, i.e., 12.04 p.m. The mean time of floret bud loosening ranged from 7.20 a.m. to 12.04 p.m. among 15 genotypes studied. Mahawer and Misra (1993) observed floret bud loosening between 9.00 and 10.00 a.m. in five genotypes studied. In the present finding, more numbers of genotypes were studied than in their study. Therefore, longer duration of time, i.e., from 7.20 a.m. and 12.04 p.m. was observed in the present study.

The mean time of complete floret opening was early in 'Hybrid selection 84-7-11' (5.53 a.m.) followed by 'Shobha' (6.20 a.m.) and 'Hybrid selection 87-221' (9.43 a.m.). Whereas, it was late in genotypes viz., 'Dhiraj' (11.56 a.m.), 'Tilak' (11.41 a.m.) and 'Arka Kesar' (11.40 a.m.). In the present study, complete floret opening time ranged from $5.53 \mathrm{a}$ am. to $11.56 \mathrm{a} . \mathrm{m}$. among 15 genotypes studied. Whereas, Mahawer and Misra (1993) observed complete opening of floret between 9.05 a.m. and 2.00 p.m. in five genotypes. The differences found in two separate studies were due to variations of genotypic, geographic and climatic conditions.

In the present study the mean time of initiation of anther dehiscence was the earliest at 5.59 a.m. in 'Gladiolus callianthus'. Also in this genotype the mean time for the completion of anther dehiscence was early (10.09 a.m.). The mean time for completion 
of anther dehiscence was between 10.09 a.m. and 2.17 p.m.; however, Shah et al. (1988) observed the anther dehiscence completion till 12.00 noon. The differences are due to genotypic and environmental effects. The mean time for initiation of stigma receptivity was comparatively early in genotypes viz., 'Hybrid selection 84-7-11' (9.13 a.m.), 'Psittacinus hybrid'(9.20) a.m. and 'Pink Friendship' at 9.38 a.m. but it was remarkably late in 'Darshan' (3.50 p.m.). Mean time for the completion of stigma receptivity was comparatively eary in genotypes viz., 'Gladiolus callianthus' (6.41 a.m.), 'Pink Friendship' (7.57 a.m.) and 'Shobha' (8.56 a.m.). It was late in genotypes viz., 'Kum Kum' (3.53 p.m.), 'Hybrid selection $88-4-8$ ' (3.20 p.m.) and 'Psittacinus hybrid' (2.53 p.m.).

The duration of the first floret loosening to complete opening of the first floret was relatively short in genotype viz., 'Shobha' (21 hours and 31 minutes), 'Hybrid selection 84-7-11' (21 hours 53 minutes). However, the duration was comparatively longer in genotypes viz., 'Tilak' (26 hours 55 minutes), 'Psittacinus hybrid' (26 hours 40 minutes) and 'Gladiolus callianthus' (26 hours 38 minutes). Mahawer and Misra (1993) studied floral biology in different genotypes, and they recorded that the hours from anthesis initiation to full anthesis varied from 23 hours 7 minutes in 'American Beauty' to 28 hours 56 minutes in 'Oscar'. In the present study, hours from basal floret opening to complete opening of floret varied from 21 hours 31 minutes in 'Shobha' to 26 hours 55 minutes in 'Tilak'. The little variation from the findings of Mahawer and Misra (1993) is because of varietal difference.

The duration of initiation of anther dehiscence to completion of anther dehiscence was comparatively shorter in genotype viz., 'Shobha' 'Hybrid selection 884-8' and 'Pink Friendship'. It was comparatively longer in the genotypes viz., 'Psittacinus hybrid' and 'Hybrid selection 82-11-22', 'Darshan' and 'Hybrid selection 847-11'.Duration of stigma receptivity initiation to stigma receptivity completion was comparatively longer in genotypes viz., 'Hybrid selection 87-22-1', 'Tilak' and 'Hybrid selection 87-1-1' while comparatively shorter duration of stigma receptivity initiation to stigma receptivity completion was found in genotypes viz., 'Hybrid selection 88-4-8', 'Hybrid selection 84-7-11' and 'Arka Kesar'. Among the 15 genotypes the stigma receptivity period was variable from 3 days 1 hour 40 minutes to 4 days 1 hour 37 minutes in the present study. This finding is in close conformity with the finding of Singh and Singh (1985) as they reported that stigma became receptive one day before anthesis and remained up to three days after anthesis. Roychaudhury (1980) observed stigma to be receptive only for 24 hours in Psittacinus hybrid under Kalyani (West Bengal) conditions whereas in the present study it was 3 days 18 hours 33 minutes. This is mainly due to the environmental effect.

\section{References}

Katwate, S.M., M.T. Patil, B.R. Singh, D.S. Karade, S.B. Gurav and C.A. Nimbalkar. 2005. Phule Ganesh: A promising gladiolus genotype. Journal of Ornamental Horticulture, 8(4): 299-302.

Kumar, R. and D.S. Yadav. 2006. Evaluation of gladiolus cultivars under sub-tropical hills of Meghalaya. (Abstr.). National Symposium on Ornamental Bulbous Crops (5-6 December). pp.33.

Mahawer, L.N. and R.L. Misra.1993. Studies on gladiolus pollination with regard to stages of anther and stigma. Journal of Ornamental Horticulture 1(2): 51-54.

Mohanty, C.R.2006.Evaluation of performance of some gladiolus varieties under Eastern Ghat high land zone. (Abstr.). National Symposium on Ornamental Bulbous Crops (5-6 December), pp. 32.

Nagraju, V. and V.A. Parthasarathy. 2001. Evaluation of gladiolus germplasm at midhills of Meghalaya. Indian Journal of Horticulture 58(3): 269-275.

Nazir, M. and V.K. Dwivedi. 2006. Evaluation of gladiolus cultivars for cut flower production for Western U.P. Journal of Asian Horticulture 2(3 \& 4): 222-228.

Roychaudhury, N. 1980. Floral biology of gladiolus. Lal Bagh Journal of Mysore, 20 (4): 36-38.

Shah, A., C.C. Pant and S.D. Lal.1988. Floral biology of some gladiolus cultivars under temperate condition. Progress in Horticulture 20(1-2): 134-135.

Singh, R. and M. Singh. 1985. Studies on floral biology in gladiolus. Progress in Horticulture 17(2): 134-135. 
Nepal Journal of Science and Technology 10 (2009) 